\title{
Percutaneous CT-Guided Core Needle Biopsies of Head and Neck Masses: Technique, Histopathologic Yield, and Safety at a Single Academic Institution
}

\author{
(D)T.J. Hillen, (DJ.C. Baker, (DJ.R. Long, (D) M.V. Friedman, and (DJ.W. Jennings
}

\begin{abstract}
BACKGROUND AND PURPOSE: CT-guided head and neck biopsies can be challenging due to the anatomy and adjacent critical structures but can often obviate the need for open biopsy. A few studies and review articles have described approaches to biopsy in the head and neck. This retrospective study evaluated technical considerations, histopathologic yield, and safety in CT-guided head and neck core needle biopsies.
\end{abstract}

MATERIALS AND METHODS: A retrospective review of head and neck biopsies performed from January 2013 through December 2019 was conducted. Clinical diagnosis and indication, patient demographics, mass location and size, biopsy needle type, technical approach, dose-length product, sedation details, complications, diagnostic histopathologic yield, and the use of iodinated contrast were recorded for each case.

RESULTS: A total of 27 CT-guided head and neck core needle biopsies were performed in 26 patients. The diagnostic sample rate was $100 \%$ (27/27). A concordant histopathologic diagnosis was obtained in 93\% (25/27) of cases. There was a single complication of core needle biopsy, a small asymptomatic superficial hematoma.

CONCLUSIONS: Percutaneous CT-guided biopsy of deep masses in the head and neck is safe and effective with careful biopsy planning and has a high diagnostic yield that can obviate the need for open biopsy.

ABBREVIATION: CTCAE $=$ Common Terminology Criteria for Adverse Events

l:

the United States, $>60,000$ new cases of head and neck cancer will be diagnosed in 2020, comprising approximately $4 \%$ of new cancer cases in men. ${ }^{1}$ Many of these cancers that arise within the oropharynx are diagnosed by an otolaryngologist using direct visualization by laryngoscopy. Most of the superficial soft-tissue masses in the neck are biopsied either by palpation ${ }^{2}$ or sonographic guidance. ${ }^{3-6}$ The masses within the deep spaces of the neck are most commonly biopsied using CT guidance. In the past, many of these deep head and neck biopsies were performed using CT guidance and fine-needle aspiration techniques. ${ }^{7-10}$ More recent articles have described the use of CT guidance and spring-loaded core biopsy needles. ${ }^{11-15}$

Received April 30, 2020; accepted after revision July 7.

From the Mallinckrodt Institute of Radiology (T.J.H., J.C.B., M.V.F, J.W.J.),

Musculoskeletal Section, Washington University School of Medicine, St. Louis, Missouri; and Musculoskeletal Radiology (J.R.L.), Mayo Clinic Arizona, Phoenix, Arizona.

Please address correspondence to Travis J. Hillen, MD, Washington University School of Medicine, Mallinckrodt Institute of Radiology, Musculoskeletal Section, Campus Box 8131, 510 S Kingshighway Blvd, St. Louis MO 63110; e-mail: tjhillen@wustl.edu; @travisjhillen

http://dx.doi.org/10.3174/ajnr.A6784
Compared with other biopsies, deep head and neck masses are difficult to biopsy safely and effectively due to the critical anatomy in the region of the biopsies, including nerves, vessels, and salivary glands. Despite the critical anatomy, there are few reported serious complications in head and neck soft-tissue biopsies. ${ }^{16}$

In general, the demand for percutaneous CT-guided biopsies continues to increase due to the evolving requirements of clinical treatment and study protocols. The well-published safety, efficacy, and high histopathologic yield obviates the need for open biopsies; however, there are relatively few publications addressing CT-guided soft-tissue core biopsies of the head and neck.

The purposes of this retrospective original research are to describe and expand technical considerations, including the use of CT angiography, and to demonstrate the high histopathologic yield and safety of CT-guided head and neck soft-tissue core biopsies.

\section{MATERIALS AND METHODS}

\section{Patient Selection and Study Enrollment}

Approval from the institutional review board was granted with a waiver of informed consent for this Health Insurance Portability and Accountability Act-compliant retrospective study. Correlating 
data were collected for all CT-guided head and neck biopsies performed at Washington University in St. Louis from January 2013 to December 2019 included in this study. These data were acquired by searching the radiology information system for neck biopsy cases using a combination of Current Procedural Terminology codes for neck/thorax biopsy (21550), soft-tissue mass biopsy (20206), and CT guidance (77012) and using the following search terms: "neck biopsy," "parapharyngeal space," "masticator space," "carotid space," and "paraspinal." Inclusion criteria were CT guidance, suspicion of

\section{Table 1: Biopsy needles by size and brand used for 27 biopsies}

\begin{tabular}{lc}
\hline Size and Brand & No. \\
\hline Biopsy needle gauge & \\
14-ga & 14 \\
16-ga & 6 \\
18-ga & 6 \\
20-ga & 1 \\
Needle brand & \\
Bard Mission & 13 \\
Achieve & 9 \\
Unknown & 5 \\
Arrow OnControl & $2^{\mathrm{a}}$ \\
\hline
\end{tabular}

${ }^{a}$ The OnControl needle used for access in 2 cases followed by coaxial placement of a soft-tissue needle. either benign or malignant tumor, soft-tissue mass, core needle biopsy, and follow-up available in the electronic medical record. CTguided biopsies for infection or superficial neck lymph nodes were excluded. For each case, we collected and evaluated the following data: patient demographics, clinical diagnosis and indication, mass size and location, biopsy needle type/gauge, technical approach, number and length of each soft-tissue biopsy, CT dose-length product, sedation details, and diagnostic histopathologic yield. Procedural complications were documented according to the Common Terminology Criteria for Adverse Events (CTCAE), Version 5.0. ${ }^{17}$ Patients were clinically monitored for at least 1 hour after each procedure for evidence of acute complications such as hematoma formation or neurologic injury. A short-term follow-up phone call between 1 and 3 days following the procedure was used to document any additional short-term complications. The electronic medical records were also reviewed for evidence of delayed complications within 30 days of the biopsy.

\section{Biopsy Procedure}

All procedures were performed by 1 of 4 board-certified fellowship-trained musculoskeletal radiologists with 12, 10, 7, and 6 years of experience. Twenty-three of the 27 procedures were
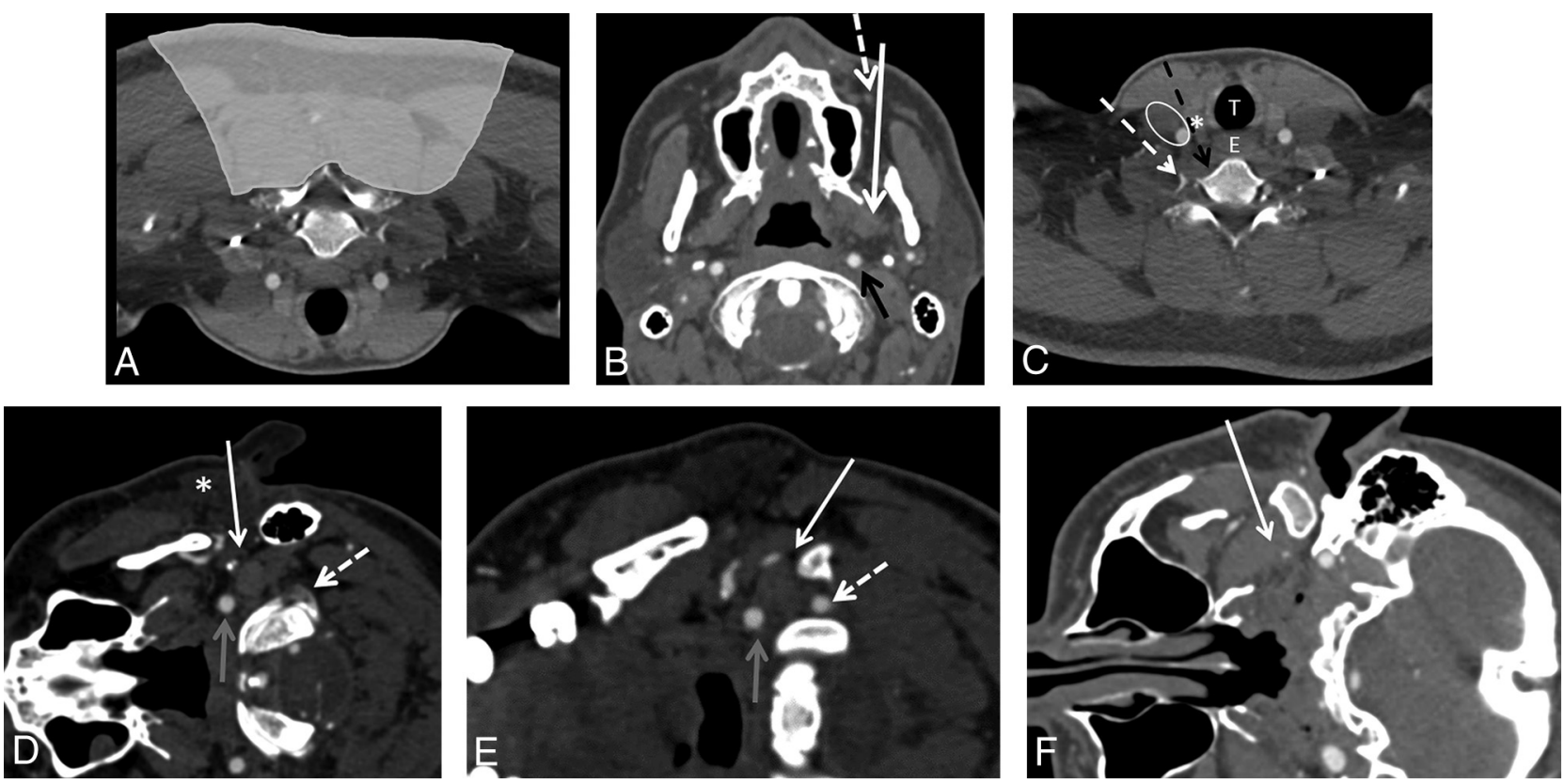

FIG 1. CT-guided neck biopsies can be performed using multiple different approaches depending on the location of the lesion. In almost all approaches, there are critical neural and vascular structures adjacent to the needle tract. A, CT angiogram of the neck flipped vertically to depict prone positioning for a posterior-approach neck biopsy. Neck biopsies in the shaded region would commonly be performed using a posterior approach. In the shaded region, there are no critical neurovascular structures. B, CT angiogram soft-tissue-windowed image of the neck with the patient in a supine position for the paramaxillary approach (white arrow). The needle course is between the maxillary sinus and the mandible adjacent to the facial artery (dashed arrow) through the buccal space. This approach can be used for lesions in the buccal, masticator, parapharyngeal, retropharyngeal, and carotid sheath spaces. The critical structures to avoid include the facial artery (dashed arrow) and the internal carotid artery (black arrow). C, CT angiogram of the neck with the patient in a supine position for anterior-approach biopsies, which can be either medial (black dashed arrow) or lateral (dashed white arrow) to the carotid and jugular vasculature (white oval). These approaches can be used for lesions in the infrahyoid neck and lower cervical vertebrae. The critical structures to avoid include the carotid artery, jugular vein, and vagus nerve (white oval); the trachea (white T); the esophagus (white E); and the thyroid gland (white asterisk). CT angiograms of the neck with the patient in a decubitus position: This positioning will be used for the retromandibular $(D)$, submastoid $(E)$, and subzygomatic $(F)$ approaches denoted by white arrows. Note that the needle will sometimes pass through a portion of the parotid gland for the retromandibular approach (white asterisk). Critical structures to avoid include the carotid (gray arrows) and vertebral arteries (dashed white arrows) with the retromandibular and submastoid approaches and the retromandibular vein in the retromandibular approach because of its proximity to the facial nerve. These approaches can be used for lesions in the deep parotid, parapharyngeal, pharyngeal, and retropharyngeal spaces. 
Table 2: Neck biopsy approach

\begin{tabular}{lc}
\hline \multicolumn{1}{c}{ Approach } & No. \\
\hline Anterior & 7 \\
Paramaxillary & 2 \\
Posterior & 5 \\
Retromandibular & 2 \\
Submastoid & 8 \\
Subzygomatic/sigmoid notch & 3 \\
\hline
\end{tabular}
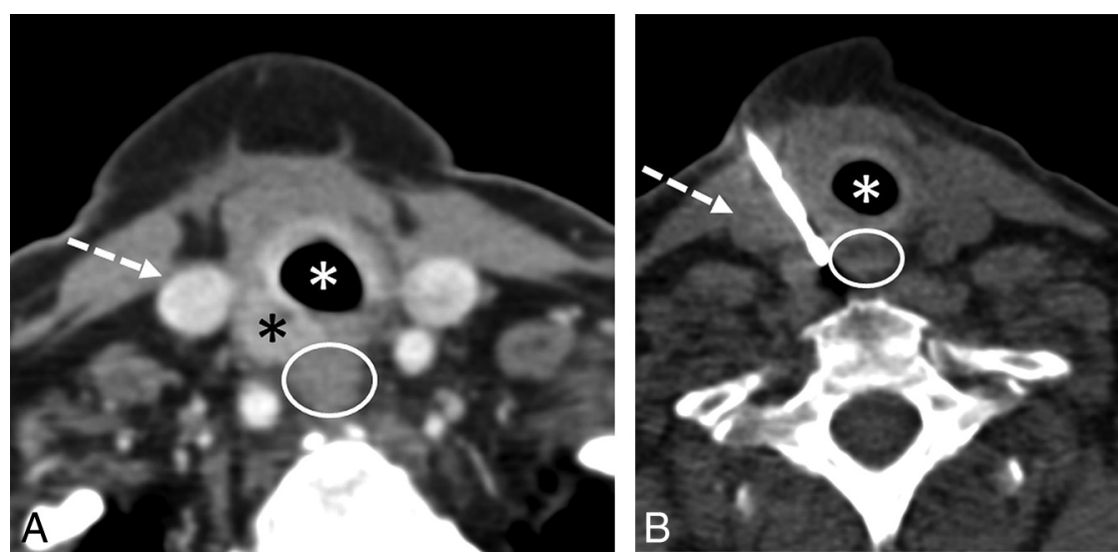

FIG 2. A 74-year-old woman with a previously excised papillary thyroid carcinoma also treated with radioactive iodine who has a new mass in the right visceral space of the neck adjacent to the thyroidectomy bed. Axial contrast-enhanced CT image (A) from a neck CT demonstrates an enhancing mass (black asterisk) in the right visceral space abutting the trachea (white asterisk), the esophagus (white oval), and the right internal jugular vein (dashed white arrow). Intraprocedural axial CT soft-tissue-windowed image $(B)$ with the core biopsy needle in place. An anterior approach was chosen to pass just medial to the internal jugular vein (dashed white arrow), just lateral to the trachea (white asterisk), and stopping short of the esophagus (white oval). The histopathology from the biopsy was recurrent papillary thyroid carcinoma.
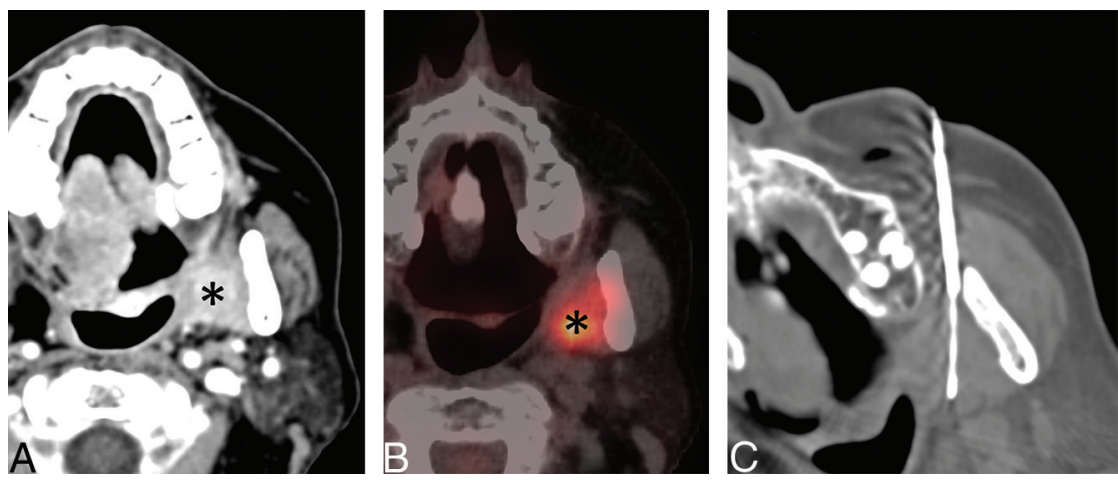

FIG 3. A 75-year-old woman with previously excised and re-excised left base-of-tongue and retromolar squamous cell carcinoma. Axial contrast-enhanced neck CT (A) and fused PET/CT (B) images demonstrate an enhancing FDG avid mass (black asterisk) in the left masticator space. A paramaxillary approach was chosen to perform the biopsy $(C)$. The histopathology from the biopsy was recurrent squamous cell carcinoma. With this biopsy, the facial artery is medial to the needle-entry site just anterior to the maxilla and is not problematic for the needle path.

on without injuring those structures.

For lesions with minimal clearance between the needle path and a critical neurovascular structure, a smaller gauge needle was chosen, either 18 or 20 ga. The outer introducer needle was placed just proximal to the target mass followed by the coaxial placement of the spring-loaded biopsy needle into the mass. In 2 cases, the Arrow OnControl battery-powered bone biopsy system (Teleflex) was used to access the softtissue lesions. Table 1 describes in detail the different biopsy needles used for lesion biopsy. The most common needle used was 14 gauge in 14/27 biopsy procedures. The average number of biopsy cores acquired was 4.4 (range, 2-9). Patient positioning on the table was dependent on the location of the head and neck lesion and the approach used to perform the biopsy.

There are multiple described approaches for biopsies in the head and neck, depending on the locations of the masses. ${ }^{18-21}$ A brief description and the approximate needle course for the different biopsy approaches are presented in Fig 1. Biopsy approaches for the patients in our group included the following: anterior $7 / 27$, paramaxillary $2 /$ 27 , posterior $5 / 27$, retromandibular $2 /$ 27 , submastoid $8 / 27$, and subzygomatic/sigmoid notch 3/27 (Table 2). The anterior approach was used for lesions in the perivertebral, anterior cervical, prevertebral, visceral (Fig 2), and pharyngeal spaces. The paramaxillary approach was used for lesions in the masticator and parapharyngeal spaces (Fig 3). The posterior approach was used for posterior perivertebral lesions. The retromandibular approach was used for parapharyngeal space lesions (Fig 4). The submastoid approach was

performed with conscious sedation; $2 / 27$, with general anesthesia; and $2 / 27$, with local anesthetic only. In most cases, a 1:1 mixture of bupivacaine $0.25 \%$ and lidocaine $1 \%$ was first administered for subcutaneous and deep anesthesia. The average sedation time for the conscious sedation cases was 43 minutes. The average intravenous used for lesions in the perivertebral, parapharyngeal, and carotid spaces (Fig 5). The subzygomatic approach was used for lesions in the masticator space.

CT angiography was performed immediately before the biopsy when the pathway to the soft-tissue mass included important 

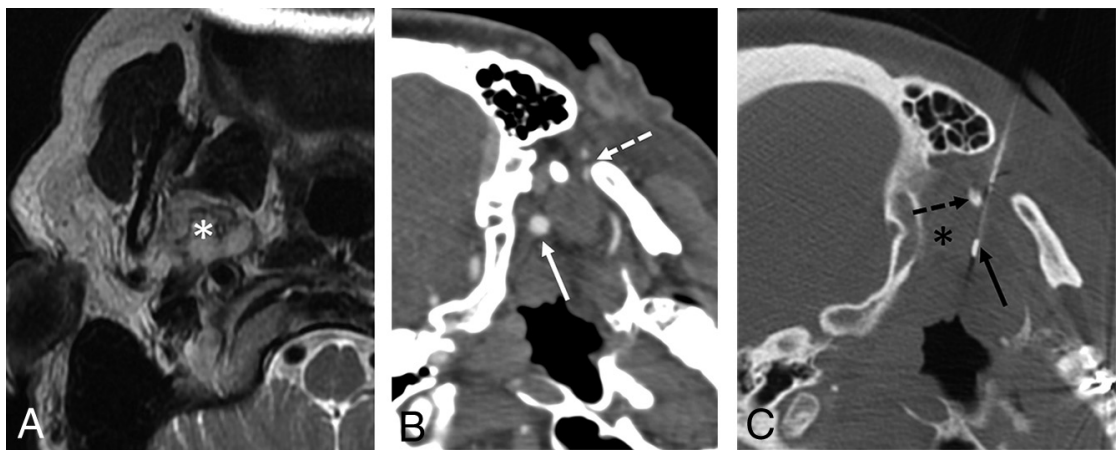

FIG 4. A 69-year-old woman with an incidentally found right-neck mass on a cervical spine MR imaging. Axial T2-weighted MR image (A) from a cervical spine MR imaging demonstrates an indeterminate T2-hyperintense mass (white asterisk) at the deep margin of the parotid gland, centered within the parapharyngeal space posterior to the masticator space. Intraprocedural contrast-enhanced soft-tissue-windowed CT image $(B)$ with the patient in the left lateral decubitus position. Note the internal carotid artery (white arrow) and other vascular structures including the retromandibular vessels adjacent to the mandibular ramus (white dashed arrow). Intraprocedural axial CT bone-windowed image $(C)$ with the core biopsy needle in place (black arrow). A retromandibular course with the entry point posterior to the ear was chosen to access the mass. The needle path is to avoid the vascular structures adjacent to the mandibular ramus, including the retromandibular vein, but anterior to the styloid process (black dashed arrow) and internal carotid artery (approximately at the site of the black asterisk but occult on noncontrast CT). The pathology was adenoid cystic carcinoma.
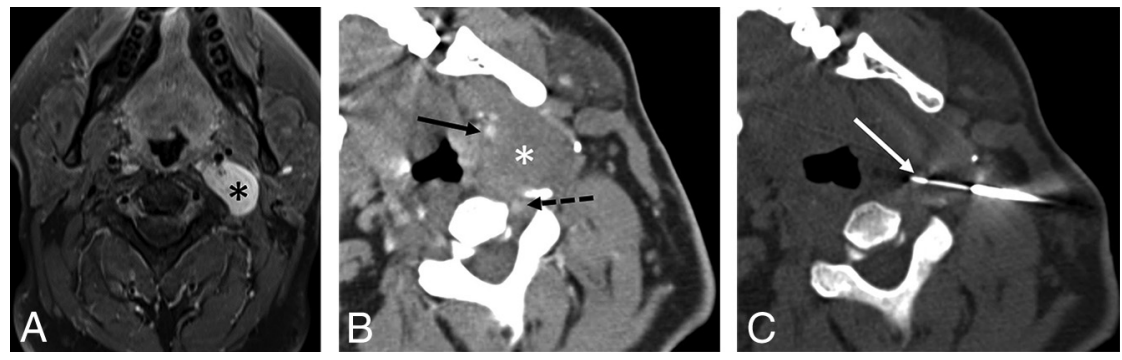

FIG 5. A 25-year-old man with neurofibromatosis type 1, new vagus nerve-related symptoms, and a enlarging painful left carotid space mass. Axial Tl-weighted fat-suppressed postcontrast MR image ( $A$ ) from a neck MR imaging demonstrates an enhancing carotid space mass (black asterisk). Intraprocedural contrast-enhanced soft-tissue-windowed CT image $(B)$ with the patient supine but with the head turned to the right. Note that the mass (white asterisk) is located between the internal carotid (black arrow) and vertebral (black dashed) arteries and is pushing the carotid artery anteriorly. Intraprocedural axial CT soft-tissue-windowed image $(C)$ with the core biopsy needle in place (white arrow). A submastoid approach was chosen to avoid the carotid and vertebral arteries. The histopathology from the biopsy was neurofibroma. Given the progressive symptoms, concern for sampling error, and the high risk given the diagnosis of type neurofibromatosis 1 , the mass was excised and final pathology was plexiform neurofibroma containing focal areas of low-grade malignant peripheral nerve sheath tumor.

vascular structures, to better delineate the vascular anatomy and plan the safest biopsy route while minimizing the risk of vascular injury. Of the 27 biopsy procedures, 10 had corresponding CT angiograms with a dose average of $80 \mathrm{~mL}$ of ioversol contrast (Optiray 350; Mallinckrodt) given intravenously (Figs 4 and 5).

\section{RESULTS}

\section{Patient Characteristics}

A total of 26 patients underwent 27 CT-guided head and neck soft-tissue biopsies. Fifty-four percent of the patients were men, and $46 \%$ were women. The age range of the patients was from 3 months to 77 years of age, with an average age of 54.7 years. The clinical concern in these cases was for primary tumor in $52 \%$ (14/27), locoregional recurrent disease in $33 \%(9 / 27)$, or metastatic disease in $15 \%$ (4/27). One complication of core needle biopsy occurred. This was a small intraprocedural hematoma (CTCAE grade 1), which was asymptomatic and required no further treatment or follow-up. Additionally, there was an adverse event in which the patient developed new asymptomatic atrial fibrillation with a rapid ventricular response (CTCAE grade 3) during positioning and the initial contrast-enhanced CT scan for localization of tumor. This was before administration of sedation medications and beginning the biopsy procedure. This patient was transported to the emergency department for heart rate control, and the biopsy was performed at a later date without complications.

\section{Lesion Characteristics and Histopathology}

The average size of the biopsied masses measured in the longest axis of each lesion was $33 \mathrm{~mm}$, ranging between 14 and $71 \mathrm{~mm}$. The locations of the lesions were the following: the anterior cervical space, $11 \%$ (3/27); carotid space, $11 \%$ (3/27); masticator space, $19 \%(5 / 27)$; parapharyngeal space, $22 \%$ (6/27); perivertebral space, $26 \%$ (7/27); pharyngeal space, $4 \%$ (1/27); prevertebral space, $4 \%(1 / 27)$; and visceral space, $4 \%$ (1/ 27) (Table 3).

A sufficient sample was obtained for histopathologic diagnosis in $100 \%$ (27/27) of the biopsies. The pathology obtained was malignant in 16/27 biopsies and benign in 11/27 biopsies. Two of the 11 benign biopsies were found to be discordant with the clinical impression and repeat biopsy results were subsequently found to be malignant. One was initially diagnosed as fibrosis with a foreign body giant cell reaction and was later found to be recurrent squamous cell carcinoma on a repeat CT-guided biopsy 6 weeks later. The second was initially diagnosed as benign neurofibroma, but at excision, it was found to have areas of malignant peripheral nerve sheath tumor within the lesion. The remaining 9 benign lesion biopsies either demonstrated no concerning change on imaging follow-up in 56\% (5/9) or were confirmed benign by excision in the remaining $44 \%$ (4/9). The most 
Table 3: Anatomic location of the target mass in 27 biopsy procedures

\begin{tabular}{lc}
\hline Target Lesion & No. \\
\hline Anterior cervical & 3 \\
Carotid space & 3 \\
Masticator space & 5 \\
Parapharyngeal & 6 \\
Perivertebral & 7 \\
Pharyngeal & 1 \\
Prevertebral & 1 \\
Visceral space & 1 \\
\hline
\end{tabular}

Table 4: Histopathologic results of CT-guided head and neck biopsies

\begin{tabular}{|c|c|}
\hline Histopathology & No. \\
\hline Acute on chronic inflammation & 1 \\
\hline Adenoid cystic carcinoma $^{a}$ & 1 \\
\hline Atypical melanin rich neoplasm ${ }^{a}$ & 1 \\
\hline Benign fibrocollagenous tissue & 1 \\
\hline Chondroid lesion & 1 \\
\hline Fibrosis with foreign body giant cell reaction & $1^{\mathrm{b}}$ \\
\hline Granulation tissue & 1 \\
\hline Metastatic myxoid liposarcoma ${ }^{a}$ & 1 \\
\hline Malignant peripheral nerve sheath tumor ${ }^{a}$ & 2 \\
\hline Myxoma & 1 \\
\hline Neurofibroma & $1^{\mathrm{b}}$ \\
\hline Papillary thyroid cancer ${ }^{a}$ & 1 \\
\hline Pleomorphic adenoma & 1 \\
\hline Round cell sarcoma ${ }^{a}$ & 1 \\
\hline Schwannoma & 2 \\
\hline Spindle cell neoplasm ${ }^{a}$ & 1 \\
\hline Squamous cell carcinoma ${ }^{a}$ & 8 \\
\hline Synovial cyst & 1 \\
\hline
\end{tabular}

a Malignant.

${ }^{b}$ Two cases with discordant histopathology. The fibrosis with foreign body giant cell reaction was found to be recurrent squamous cell carcinoma on repeat CTguided biopsy. The neurofibroma was found to have components of malignant peripheral nerve sheath tumor when excised.

common malignant lesion was squamous cell carcinoma, found in 8 patients (Table 4). The overall concordance of the biopsies was $93 \%$.

\section{CT Radiation Dose}

The dose-length product ranged from 76 to $2790 \mathrm{mGy} \times \mathrm{cm}$, with an average of $533 \mathrm{mGy} \times \mathrm{cm}$. When we considered the most recent biopsies, specifically from January 2015 to December 2019, which account for $89 \%$ (24/27) of all biopsies performed, there was a decreased average dose-length product of $455 \mathrm{mGy} \times \mathrm{cm}$. The highest dose-length product recorded was $2790 \mathrm{mGy} \times \mathrm{cm}$. This was performed before increased awareness of scanning parameters, advanced scanner technology, as well as institutional emphasis on decreasing diagnostic and procedural radiation doses.

\section{DISCUSSION}

Masses in the head and neck arise in multiple different anatomic spaces and have a wide variety of tumor histopathologies. Diagnosis and treatment require a multidisciplinary approach, which is constantly evolving. ${ }^{22-24}$ Often, the tissue required for diagnosis is acquired by a subspecialty-trained radiologist, particularly when the mass is located within a deep neck space requiring CT guidance for biopsy access.

Multiple publications have demonstrated the safety and utility of soft-tissue biopsies in general, but few have focused specifically on the deep head and neck. ${ }^{7-15}$ Most complications reported in the literature in these studies are minor, including small hematoma, pain, vasovagal reaction, and minor infection. ${ }^{7-15}$ Another more rarely described complication is seeding of tumor along the biopsy needle tract. A MEDLINE data base search between 1970 and 2014 found 7 reported cases of tumor seeding, 5 with fine-needle aspiration and 2 with core needle biopsy, in the 610 articles reviewed. ${ }^{25}$ These findings are similar to those in our study in which we report 1 minor complication of the biopsy procedure, no tumor seeding complications, and 1 adverse event before beginning the biopsy procedure, which was unlikely related to the procedure, given that this occurred before a needle was placed in the neck. The only reported major complication related to a CT-guided head and neck biopsy in the literature was an internal maxillary artery pseudoaneurysm presenting 3 months after the CT-guided fine-needle aspiration. This was thought to be due to an increased risk from prior radical neck surgery and radiation therapy, leading to abnormal neoangiogenic vascularity or large-vessel vasculopathy. ${ }^{16}$

Given the relatively high-stakes anatomy in the head and neck, choosing the appropriate anatomic approach to safely perform the biopsy is of the utmost importance. There are multiple described approaches to head and neck masses, with some overlap in the ability to access a deep neck space. ${ }^{18-21}$ For example, pathways to reach the parapharyngeal, masticator, and pharyngeal spaces may include paramaxillary, retromandibular, submastoid, and subzygomatic approaches. Thus, it is important to fully evaluate the preprocedural imaging for the location of vessels, nerves, salivary glands, and salivary ducts to find the safest and most direct needle course. The CT angiography technique increases the certainty and safety of the needle path chosen for the procedure, particularly when positioning for the procedure is different from the standard supine position typically used for CT imaging and when there are arteries in or directly adjacent to the targeted mass. This technique has been previously described in cervical spine biopsies, ${ }^{26}$ but not in biopsies of head and neck masses. All except 2 of the 27 cases were performed with either conscious sedation or local anesthesia, increasing the safety of the biopsy in this patient population, which is typically considered at higher risk for general anesthesia.

The choice of biopsy technique, fine-needle aspiration versus core needle biopsy, is often dependent on the institution. At our institution, core needle biopsies are preferred by the pathologist when feasible for increased diagnostic certainty. In previous clinical series, the yield of both CT-guided fine-needle aspiration and core biopsy of the head and neck soft tissues is varied. In the largest study of 216 patients who underwent CT-guided fine-needle aspiration, a diagnostic sample was obtained in $90 \%$ of patients, with a concordant diagnosis in $88 \%$ of cases. ${ }^{9}$ Studies of CT-guided core biopsies have reported diagnostic yields ranging from $73 \%$ to 96\%. ${ }^{12-15}$ Compared with these prior CT-guided soft-tissue mass biopsy series, our diagnostic yield is similar-to-slightly higher, with $100 \%$ of samples sufficient for histopathologic diagnosis and a concordant diagnosis in 93\% (25/27) of all biopsies. This result may be 
due to the larger average needle gauge used in our study, most commonly 14 gauge, and the higher average number of core specimens obtained of 4.4 .

\section{CONCLUSIONS}

This original research demonstrates the safety and efficacy of CTguided percutaneous core biopsy for deep soft-tissue masses in the head and neck, obviating the need for open biopsies and their associated risks in locations not easily accessible by palpation, sonography, or laryngoscopy. It also describes the use of CT angiography for vessel localization and mapping before needle placement following patient positioning on the procedural table to reduce the risk of vascular injury.

Disclosures: Travis J. Hillen-UNRELATED: Consultancy: Medtronic, SI BONE, Ultragenyx Pharmaceutical, ERT, Comments: paid consultant for studies not related to published work. Jack W. Jennings-RELATED: Consulting Fee or Honorarium: Bard/BD and Stryker, Comments: Both are for consultation for the bone biopsy system and nothing to do with this article; UNRELATED: Consultancy: Merit, Medtronic, Comments: Merit contract ended June 30, 2020, Medtronic monitoring for OPuS 1 spine ablation trial.

\section{REFERENCES}

1. American Cancer Society. Cancer Facts and Figures 2020. https://www. cancer.org/content/dam/cancer-org/research/cancer-facts-and-statistics/ annual-cancer-facts-and-figures/2020/cancer-facts-and-figures-2020.pdf. Accessed April 13, 2020

2. Nyquist GG, Tom WD, Mui S. Automatic core needle biopsy: a diagnostic option for head and neck masses. Arch Otolaryngol Head Neck Surg 2008;134:184-89 CrossRef Medline

3. Pfeiffer J, Kayser G, Technau-Ihling K, et al. Ultrasound-guided coreneedle biopsy in the diagnosis of head and neck masses: indications, technique, and results. Head Neck 2007;29:1033-40 CrossRef Medline

4. Novoa E, Gurtler N, Arnoux A, et al. Role of ultrasound-guided core-needle biopsy in the assessment of head and neck lesions: a meta-analysis and systematic review of the literature. Head Neck 2012;34:1497-1503 CrossRef Medline

5. Douville NJ, Bradford CR. Comparison of ultrasound-guided core biopsy versus fine-needle aspiration biopsy in the evaluation of salivary gland lesions. Head Neck 2013;35:1657-61 CrossRef Medline

6. Pfeiffer J, Ridder GJ. Diagnostic value of ultrasound-guided core needle biopsy in patients with salivary gland masses. Int $J$ Oral Maxillofac Surg 2012;41:437-43 CrossRef Medline

7. Gatenby RA, Mulhern CB, Strawitz J. CT guided percutaneous biopsies of head and neck masses. Radiology 1983;146:717-19 CrossRef Medline

8. DelGaudio JM, Dillard DG, Albritton FD, et al. Computed tomography-guided needle biopsy of head and neck lesions. Arch Otolaryngol Head Neck Surg 2000;126:366-70 CrossRef Medline

9. Sherman PM, Yousem DM, Loevner LA. CT-guided aspirations in the head and neck: assessment of the first 216 cases. AJNR Am J Neuroradiol 2004;25:1603-07 Medline
10. Sack MJ, Weber RS, Weinstein GS, et al. Image-guided fine-needle aspiration of the head and neck: five years' experience. Arch Otolaryngol Head Neck Surg 1998;124:1155-61 CrossRef Medline

11. Mukherji SK, Turetsky D, Tart RP, et al. A technique for core biopsies of head and neck masses. AJNR Am J Neuroradiol 1994;15:51820 Medline

12. Connor SEJ, Chaudhary N. CT-guided percutaneous core biopsy of deep face and skull-base lesions. Clin Radiol 2008;63:986-94 CrossRef Medline

13. Wu EH, Chen YL, Wu YM, et al. CT-guided core needle biopsy of deep suprahyoid head and neck lesions. Korean J Radiol 2013;14:299306 CrossRef Medline

14. Wu EH, Chen YL, Toh CH, et al. CT-guided core needle biopsy of deep suprahyoid head and neck lesions in untreated patients. Interv Neuroradiol 2013;19:365-69 CrossRef Medline

15. Cunningham JD, McCusker MW, Power S, et al. Accessible or inaccessible? Diagnostic efficacy of CT-guided core biopsies of head and neck masses. Cardiovasc Intervent Radiol 2015;38:422-29 CrossRef Medline

16. Walker AT, Chaloupka JC, Putman CM, et al. Sentinel transoral hemorrhage from a pseudoaneurysm of the internal maxillary artery: a complication of CT-guided biopsy of the masticator space. AJNR Am J Neuroradiol 1996;17:377-81 Medline

17. US Department of Health and Human Services. Common terminology criteria for adverse events (CTCAE), Version 5.0. https://ctep.cancer. gov/protocolDevelopment/electronic_applications/docs/CTCAE_ v5_Quick_Reference_8.5x11.pdf. Accessed April 14, 2020

18. Gupta S, Henningsen JA, Wallace MJ, et al. Percutaneous biopsy of head and neck lesions with CT guidance: various approaches and relevant anatomic and technical considerations. Radiographics 2007;27:371-90 CrossRef Medline

19. McKnight CD, Glastonbury CM, Ibrahim M, et al. Techniques and approaches for safe, high-yield CT-guided suprahyoid head and neck biopsies. AJR Am J Roentgenol 2017;208:76-83 CrossRef Medline

20. Abrahams JJ. Mandibular sigmoid notch: a window for CT-guided biopsies of lesions in the peripharyngeal and skull base regions. Radiology 1998;208:695-99 CrossRef Medline

21. Tu AS, Geyer CA, Mancall AC, et al. The buccal space: a doorway for percutaneous CT-guided biopsy of the parapharyngeal region. AJNR Am J Neuroradiol 1998;19:728-31 Medline

22. Gibson MK, Forastiere AA. Multidisciplinary approaches in the management of advanced head and neck tumors: state of the art. Curr Opin Oncol 2004;16:220-24 CrossRef Medline

23. Chin D, Boyle GM, Porceddu S, et al. Head and neck cancer: past, present and future. Expert Rev Anticancer Ther 2006;6:1111-18 CrossRef Medline

24. Bradford CR. The care of the head and neck cancer patient is a team sport. JAMA Otolaryngol Head Neck Surg 2013;139:337-39 CrossRef Medline

25. Shah KS, Ethunandan M. Tumour seeding after fine-needle aspiration and core biopsy of the head and neck: systematic review. $\mathrm{Br} J$ Oral Maxillofac Surg 2016;54:260-65 CrossRef Medline

26. Wiesner EL, Hillen TJ, Long J, et al. Percutaneous CT-guided biopsies of the cervical spine: technique, histopathologic and microbiologic yield, and safety at a single academic institution. AJNR Am J Neuroradiol 2018;39:981-85 CrossRef Medline 